\title{
Methodologies for tracking learning paths: designing the online research study Making a Filmmaker
}

\author{
Lisbeth Frølunde, Danish School of Education, Aarhus University \\ Øystein Gilje, Institute for Educational Research, University of Oslo \\ Fredrik Lindstrand, Department of Didactic Science and \\ Early Childhood Education, Stockholm University \\ Lisa Öhman-Gullberg, University College of Arts Crafts and Design
}

The article concerns the design of a collaborative research project (2008-09) entitled Making a Filmmaker, which examines how young Scandinavian filmmakers create their own learning paths in formal and/or informal contexts. Our interest is how learning experiences and contexts motivate the young filmmakers: what furthers their interest and/or hinders it, and what learning patterns emerge.

The aim of this article is to present and discuss issues regarding the methodology and methods of the study, such as developing a relationship with interviewees when conducting interviews online (using MSN). We suggest two considerations about using online interviews: how the interviewees value the given subject of conversation and their familiarity with being online. The benefit of getting online communication with the young filmmakers offers ease, because it is both practical and appropriates a meeting platform that is familiar to our participants.

\section{Introduction}

This article addresses the methodology and methods used in the Scandinavian study Making $a$ Filmmaker, and in particular how written online interviews were conducted by using MSN. ${ }^{1}$ The study, which is financed by the Norwegian Media Council, ${ }^{2}$ is based on an interest in the shifting relationship between youth and their production of moving images.

In Making a Filmmaker, we (four researchers in Norway, Sweden and Denmark) study young filmmakers (age 15-20) in the Scandinavian countries in regard to how they make learning paths and find various resources for filmmaking. Our use of the term path refers to trajectories of people, places, discourses, ideas and actions (see for example Scollon \& Scollon, 2004), applied here to the paths of the agent in their actions of learning across contexts. Our interest is focused on 
how learning experiences and contexts motivate the young filmmakers: what furthers their interest and/or hinders it, and what learning patterns emerge. We are interested in cultural aspects regarding these learning patterns and processes: in the films as texts and the filmmakers as agents who bring in a set of identities (Drotner, 2003a; Kearney, 2006; Wenger, 1998) to learning filmmaking.

Apart from a general description of the methodology and methods used in the project, the article primarily discusses the advantages of using MSN as a way of conducting interviews, and relates our experience with this method to similar studies. The article is structured in three parts as follows. In the first part, we position our research design in light of related recent studies on youth and moving images and give a brief presentation of our theoretical perspectives. In the second part, we describe our methods for gathering data and discuss methodological issues. In the third part, we discuss methodology in relation to usefulness for studying learning contexts for filmmaking by youth. We conclude by reflecting on methodological issues, including written online interviews.

\section{Related research on moving image production by youth and learning and our theoretical perspective}

Our study is inspired by a number of international studies of youth and digital media production - including from a British context (Buckingham et al., 1995; Buckingham \& Sefton-Green, 1994; Buckingham, 2003, 2007; Reid \& Burn, 2002; Burn \& Parker, 2003; Burn \& Durran, 2006, 2007), digital storytelling in California (Hull, 2003; Hull \& Nelson, 2005; Hull \& Kenney, 2008), and Scandinavian research (Drotner, 1999, 2003b; Erstad et al., 2007a; Erstad \& Gilje, 2008; Lindstrand, 2006; Öhman-Gullberg, 2008; Frølunde, 2009). With these studies as our background, we try to gain new insight into filmmaking in the network society, and how young filmmakers use diverse contexts for developing as filmmakers.

Integrating topics of learning contexts and media use is common in media educational research on children and youth (see Drotner, 2001; Colley et al., 2004; Drotner \& Livingstone, 2008; SeftonGreen 2004). Many such studies are based upon the premise that youth explore and learn to use digital technologies rapidly through their participation in play and integration of technologies in their informal settings, or outside of school (Livingstone, 2002; Loveless, 2007). Educational researchers (Wenger, 1998; Halpern, 2008) are currently reconsidering the old model of mentorship for learning and describing the pedagogical importance of apprenticeship in schools, arts, and other cultural institutions.

We agree that context for learning is relevant and argue in line with media educator Julian Sefton-Green (Sefton-Green, 2008) that there is a need to tease out how learning and digital media practices come together, for instance, when youth make their own films and produce other kinds of media texts. We want to understand the how - as well as the where and why of learning in the Making a Filmmaker study.

However, designing a study to capture various learning 'paths' and contexts brings up many 
methodological considerations. For one, how to study the phenomenon of mediated contexts for media production by youth, ${ }^{3}$ contexts that are both physical and virtual?

Many empirical media research studies choose a specific context to focus on (such as a school setting or a specific after-school program). For instance, the UK-based Andrew Burn \& John Durran have followed diverse media production activities occurring at Parkside upper secondary school in a span of 10 years (Burn \& Durran, 2007; see also Burn \& Parker, 2003), while John Potter explored moving images in relation to other school subjects (Potter, 2006). Glynda Hull conducted empirical studies that include a detailed textual analysis of the digital stories made in after school programs in Oakland, CA (Hull \& Nelson, 2005). Our point is that while media research often refers to the ubiquity of multimedia in the lives of youth, it is challenging to design a study that teases out the learning experience across various learning contexts.

We want to highlight here how we study the individual paths of learning from the view of the particular young filmmakers within the limits of a small-scale study. We presume there are questions of identity for the young filmmakers, which also impact on how interviewees present themselves in interviews. Herein, we consider the overall design of the study with focus on our method of interviewing online with written dialogue, similar to chatting online, distinguished from for example, face-to-face interview or voice, video or conference-based interviewing.

\section{Our theoretical approach and research design}

The theoretical starting point of multimodality and the research interest regarding youth and digital media production have informed our research design. In the Making a Filmmaker study, we want to explore how young people engage in learning experiences, specifically around filmmaking production. Our theoretical approach is inspired by social semiotics and multimodality. Where previous forms of discourse analytical approaches have claimed that the social world is constructed through language, social semiotics and multimodality go further to say that we construct the world through all the semiotic resources we have at hand in a given situation and in all material utterances we make (Hodge \& Kress, 1988). Central to this approach is therefore an interest in understanding how people communicate and make meaning with a wide range of semiotic resources, or modes (Kress \& van Leeuwen, 2001; van Leeuwen, 2005). Apart from spoken and written language we use images, gestures, sounds and gaze to represent aspects of the world in our communication with each other. In that sense communication can be described as multimodal. However, this claim would not suffice as a theoretical stance alone. It is complemented with the emphasis of social semiotics on the social aspects of multimodal communication and meaning-making, bringing questions regarding agency, power and interest to the fore.

Viewing filmmaking as a multimodal event/process has a number of implications for thinking about learning. In our approach we treat learning as a dynamic process of sign-making (Kress et al., 2001). The interviewees' texts, the written online interviews and their films, are seen as examples of semiotic signs, shaped in ways that correspond to their interests and intentions at the time of production.

As Gunther Kress states in a recent interview in the journal Designs for Learning, ethnographic 
approaches and their focus on "what is going on" can complement a social semiotic approach "by giving further insight into interest, motivation and the shape of the environments in which signs are made" (Lindstrand, 2008: 68). Our way of combining different types of data in the way described in this article enables us, in a similar way, to grasp a broader sense of the contexts and experiences in focus of the study. The social semiotic approach enables us to combine the different research interests of the study into a coherent whole, since data simultaneously are produced at different levels. At one level the answers given in questionnaires and interviews provide us with information about the interviewees' experiences of the different areas we ask them about. At another level the same data says something about the individual interviewee, in terms of her or his interests, motivations etc. What is brought forward and thought of as interesting in relation to us and in relation to what we ask them? How are their experiences communicated and with what means?

Our research design combines quantitative and qualitative approaches. The data derives from an online survey (with 33 questions) and the written interviews (using MSN). In addition we have collected one film from each participating filmmaker (interviewee) and their written description of one particular scene in the film. Such different data calls for different analytic approaches.

In our analysis we follow two strands. First, we explore how the filmmakers report on their learning paths in regards to formal and informal learning aspects and contexts. Secondly, we do a textual analysis, inspired by multimodal analysis (Lindstrand, 2006; Öhman-Gullberg, 2008: Frølunde et al, 2007; Kress \& van Leeuwen, 2001; Burn \& Reid, 2001; Burn \& Parker, 2003), of the films sent to us by the participants in the study.

\section{Reflecting on our methodological approach}

In our endeavour to understand the process of becoming a filmmaker, we integrate online survey data with textual analysis of films and analysis of online interview data. The survey was an online questionnaire that was answered by 64 young filmmakers (age 15-20) across Denmark, Sweden and Norway. ${ }^{4}$ It offers means to see general patterns in relation to our sample, including access to digital technology - such as editing software and digital camcorders - and overall differences in the learning contexts, such as available media education courses and after-school programs in various countries. In the online survey, the 64 participants were asked if wanted to be interviewed. 55 agreed and were subsequently contacted through e-mail and follow-up postal letter. 28 sent us a copy of a film of their choice, along with a description of one particular scene in this film. ${ }^{5}$ We interviewed 29 young people in total: 9 Danes, 9 Swedes, and 11 Norwegians. We conducted 38 separate interviews. The aim of conducting the online interviews was to give us an insight into a more personal and specific knowledge about filmmaking and learning processes, including factors of identity and interest.

Despite this focus, the films also have a central role in the interviews. Films were selected and sent (along with a description of a specific scene chosen by the informant) by the individual interviewee to an interviewer before the online MSN interview occurred. The interviewers viewed the 
films made by each interviewee, and read the answers that the individual had given in the online survey, as preparation for the interview. Our integration of the film in the interviews is inspired by the social semiotic approach and photo and film elicitation methods, which are mainly used in visual sociology and visual ethnography (Banks, 2001; Pink, 2001, 2006). What characterizes these approaches is the emphasis on the agents. Especially visual ethnography stresses participation by agents in interviews with the aim of displacing some of the asymmetry in the interview situation. The young filmmaker becomes more of the expert and the researcher is the one who listens and asks questions, aware of the constructed situation. Thus, the participants' film material and choice of a film scene is co-constructing the agenda of the interview. The film material serves as a communication link between the researcher and filmmaker. In this way, the topics in our interviews revolve around issues with relation to their films, a specific scene in the film they sent us, as well as topics from the online survey (conducted previous to the interview).

Online interviews have mainly been used as a method within user studies of online sociability and computer-mediated communication. In recent years there is a growing body of research using such methods (Turkle, 1995; Markham, 1998; Hine, 2000; Scollon \& Scollon, 2004; Lüders, 2007). The Scollon and Scollon study (2004) shows how online technologies expand research methods and possibilities for education and social interaction. Christine Hine suggests virtual technologies require a new form of virtual ethnography and that online research methods challenge how researchers perform our identity as researchers. Annette Markham (1998) discusses the reflexive stance to interviews and research online and the approach of immersion on the Internet, similar to other anthropological approaches to cross-cultural understanding. Our point is that qualitative interviews online pose a number of challenges to how "we perform our identity as a researcher" (Hine, 2000: 74), in our case, initial introductory emails also acquire a major significance in the interplay of authorities and identities.

Any type of interviews can be more or less structured, from loosely described conversational themes to more precise questions (Kvale, 1996). In our case, interviews are semi-structured, with a series of themes about the filmmaker's productive experience with film and media. When meeting the participants online, the interview guides are a background checklist and questions emerge from the survey data and the flow of writing together (chatting) on MSN. But how is the interview structure affected by the written mode and meeting online and 'chatting'?

In the PhD thesis Being in Mediated Spaces by Norwegian media researcher Marika Lüders, she discusses the advantages and disadvantages of online interviewing and compares it to face-to-face interviews. She summarizes three features concerning online interviews of interest to us for our reflections: (1) the 'ease' regarding personal matters, (2) more 'precision' of replies due to editing, yet (3) the possibility of 'over-editing' of 'imperfect' replies:

First, the assumption validated in several research projects [is] that participants find it easier to talk about personal matters in mediated meetings (...) Second, written conversations yield a smaller ratio of words pr minute, yet they are more precise due to the edited character of written conversations (at least in interview situations). Third, the 
researcher needs to reflect on whether [online] interviews are over edited, as the imperfect character of oral conversations can provide interesting empirical data.

(Lüders, 2007: 36-37)

Our experience with the online MSN interviews is in line with Lüders' evaluation. We find it offers 'ease' and is more 'imperfect' (than over-edited), but, its value depends on building a relationship between interviewee and interviewer. We speculate that some young interviewees may prefer online interviews to a face-to-face setting, and might not otherwise consent to do an interview at all, as Lüders also points out. Also, it allowed us access to a geographically distributed group, across rural and urban areas of Scandinavia. However, we agree that it is necessary to reflect on the features of the online written interview as a mode of communication.

\section{Discussion and examples of developing a relationship in online interviews:}

In the following, we discuss the features of online interviews, which we divide (slightly differently than Lüders' above) into: (1) ease and (2) over-editing (and reflecting) in replies, and (3) timing (and sharing) in written online dialogue. We relate these features to developing a relationship in the interview and exemplify this with how 'bodily presence' and personal interests, revolving around filmmaking, are mediated online. Three excerpts from interviews provide examples.

Ease is prominent in the interviews in that our interviewees tell us about themselves and their urge to make films in personal terms - and likewise, we as interviewers present ourselves in a rather personal, casual way. A prime concern is developing a relationship in any interview, especially so when you cannot see each other. We find that rapport builds and we to some degree develop familiarity, for example through giving response to their films. An example of how rapport builds is through the use of 'emoticons' (smileys etc.) to supplement the written conversation. The smileys appear significant - we suggest it is because our communication becomes more embodied and humorous, as we exemplify below. The excerpt is half-way into an interview with Danish 17 year-old Maja. She frequently uses emoticons and the female interviewer gradually uses them as well. The topic in the excerpt is participation in the Oregon film festival. Maja tells she was in the audience, but did not submit her own film:

Maja: I didn't participate in the festival, unfortunately, so I did not really learn anything from it. Other than that you shouldn't be afraid to send your work to film festivals... since you have nothing to lose Interviewer: Does that mean that you otherwise hold back? Maja: yes. I believe so actually but that is also because I am rarely satisfied with what I make. it can always be better I think Interviewer: yes and is that why you don't send in a film or??? Maja: yep Interviewer: Ok. But the film industry can be elbows out - competition - many men etc. Or how do you see it? 
Maja: you hit it very well. if you really want something, you damn well have to do something for it yourself. never give up and believe in yourself.

Interviewer: hurrah!

Maja:

The above exemplifies personal contents and how the facial responses are used through the emoticons, whereby it seems to build a more familiar tone in the interview. The mode of writing does not offer facial mimicry, but the emoticons refer to this face-to-face exchange of emotion. In this case, building the relationship is also through the interviewer's written response, such as the supportive 'hurrah' to the interviewee.

Over-editing of replies and reflecting is possible in written, online interviews (Lüders, 2007). It is unclear how much editing of replies happens. We experienced pauses in the interviews between writing our questions and getting a response. Conducting written interviews online provides both the interviewer and the interviewee with time to edit replies, in order to be more precise about the written text.

Below is an example of rather slow reply time by 18 -year old Norwegian Thor, who is answering questions about his motivation for filmmaking, here if it is for fun. Thor replies 'hehe' and explicitly writes he needs time to think before answering the interviewer's question:

Thor: (20.41.44)

hehe, perhaps, I understand, I just need to go a bit into myself here and think

Thor: (20.42.03)

That it is fun is not really the only motivation

Thor: (20.45.34)

I absolutely have big goals and ambitions, and I want to give it all I have to reach them, but basically the thing is that it would be incredibly cool to reach what I dream about, and if I do actually reach it then it will be fantastic, even though probably the way there was not that easy or fun

This is an example of how pauses may be used for reflecting (the actual time is in brackets). We also used pauses for reviewing and following up on questions. In our interviews, words are often written in a 'sloppy' way and topics shift back and forth, as in oral conversation. We assume that this indicates that interviewees do not over-edit as in trying to 'perfect' written answers.

Timing is an important aspect of online written interviews. We found that reply time varies - whether due to the interviewee editing replies, typing slowly, or doing multiple tasks during the interviews (whether related to interview or not). The excerpt below also shows how films and filmmaking are integrated within the interview, here in regards to checking a site during an interview. The interviewee, 17-year old Norwegian Erik, directs the interviewer to a site: 
interviewer: (22.32.25)

What kind of sites have you used to learn about 3D animation, do you have some examples?

Erik says: (22.36.43)

The 3D program that I use is called "Blender 3D", and is incredibly advanced, a so called open source program, which means that the users can participate in developing the program. It is in this way also free of charge and there are loads of tutorials. For example, Wikipedia has a project that is called something like "Blender - Noob to Pro" and the link to the program is (www.blender.org) has loads of user manuals and links to other sites and that kind of stuff. Most of what I know now I have learned through online tutorials.

interviewer: (22.38.22)

I see. [interviewer investigates the site] It looks quite pro (...)

The point here is that the interviewee and the interviewer have separate timing due to being in different locations and not being able to see each other. However, a particular web site copied into the answer from Erik constitutes a link between interviewer and interviewee. Of course, this situation is different than interviews with video. Several interviewees mentioned that not being able to see the interviewer was 'odd', but we speculate that the feature of not seeing one another, and the different timing, relates to the surprising ease of developing relationships with the young filmmakers during online, written MSN interviews.

Timing also relates to the time used on an interview. We found that online interviewing is tiring after approximately an hour. Therefore, we experimented with doing two shorter rather than one long interview. Doing two shorter interviews usually resulted in a quicker reply pace overall, also, the second interview gained a more familiar tone.

To sum up the discussion - there are advantages and limitations when using online, written MSN interviews or any type of interview to study the learning paths to young filmmakers. We rely on written reports and do not directly study filmmaking (i.e. not making in situ observations of online practices or face-to-face filmmaking practices), but inquire into the reports by filmmakers about such practices by using a written, dialogic form of interview. As in all cases when interviews are used as a way of collecting and constructing data, one needs to consider the fact that statements and answers given by participants are discursively formed and highly dependent on social dynamics and other aspects related to the contexts of the interview. This fact becomes specifically evident when working within a social semiotic framework. From a multimodal perspective the difference between writing and talking are important issues (Kress, 2003), which need to be further explored as we continue to analyze the written data and critique our study. ${ }^{6}$

Similar to any other text, the texts produced in interviews are ideologically shaped and socially dynamic representations, generically formed to fit within the context of the interview (see Lind- 
strand, 2006 for further reflections). In addition, the use of MSN as a platform for interviews could be seen as problematic in this respect as it further enables our participants to elaborate on their on-screen identities and construct themselves according to their interests in the specific situation of the interview. However, this construction of self occurs in all interactions and is not perceived as a problem within the frames of this study, since we are interested in how the young filmmakers present their view of their possibilities, experiences and expectations.

A significant factor is the role of the films in the interviews. The dialogue about their films serves to link interviewees to something that they have made and selected to show the interviewer. The level of individual engagement is thereby (presumably) increased in the interview situation. The four interviewers in the project all find that the quality of the relationship with the interviewees is promoted when the interview topic turns to the interviewee's own films. We suggest two considerations about using online interviews: how the interviewees value the given subject of conversation and their familiarity with being online.

\section{Online interviews}

\section{- a useful approach to studying learning paths across contexts?}

In our study we seek to identify different contexts where young filmmakers (age 15-20) learn and develop through their participation (see Gilje et al., forthcoming 2009). We evaluate that the methods of online interviews and surveys are relevant for uncovering the different contexts for filmmaking. In our data we have been able to identify a range of contexts for learning about filmmaking in Scandinavia, which we summarize below, before concluding.

Based on Sefton-Green (2004, 2008), we distinguish roughly three types of contexts; informal, non-formal and formal contexts of learning.

Informal contexts relate to the participation in filmmaking that falls outside of school, it is characterized as interest driven and may be self-taught or take place in communities of interest. For instance, when the young filmmakers produce films at home, alone or with friends and family, or use web sites for meeting, exchanging and distributing films. The informal contexts have degrees of structure or formality, with deadlines and commitment to membership.

Non-formal contexts relate to film production, such as after-school programs and film festivals. Film festivals are important channels for young Scandinavian filmmakers to show films and as meeting places for encounters with peers and professionals in the film industry.

The formal contexts refer to schools. The availability of producing films in school (especially the media subject) is quite different in Norway, Sweden and Denmark. (Except for a national survey on the new media subject in Norway (Erstad et al., 2007b), this is scarcely researched.)

Given our aim of identifying a range of contexts for filmmaking, conducting written online interviews allowed us access to filmmakers across diverse contexts for filmmaking in Scandinavia. We were thus meeting them in the 'informal' context, which appears important for film-interested youth. Using the Internet for achieving information, following tutorials and publishing films are important activities for many of our participants. By interviewing the filmmakers online, we can 
'share' a site or a particular online community in the present situation of interviewing. The appropriation of the technologies of the internet mirrors, at least partially, our topic of communication, identity and learning in virtual networks (such as the Nordic site www.dvoted.net for young filmmakers).

\section{Final remarks on combining web-based survey and written online interviews}

We now return to questioning methodology, especially the value of online methods for our study. The web-based survey offers a way to see general patterns, such as differences in the patterns of using various resources and contexts, as well as get an impression of the available media education courses in various countries. The interviews give further insight, based on reports of what the young filmmakers learned, and how they perceive learning. It appears from our data that the non-formal contexts have great importance for learning for some - while the media education in school is of greater importance to others - and we can capture this by combining approaches (see Gilje et al., forthcoming 2009).

There are unclear questions and nuances in answers in the survey that get clearer by conducting interviews. For example, although $80 \%$ answer yes to having media education, many of the Danish respondents do not currently take media education in school. In the interviews it also appears that film and media courses outside of the regular school program (such as the filmmaking courses at the Danish Station Next program) were sometimes understood as 'school', and in that sense the answers to the survey were misleading. Therefore, the interviews are important for corroborating and gaining in-depth information on contexts and how they inter-relate.

The online platform for survey and interviews is significant because it gives access to youngsters in even remote parts of Scandinavia. The benefit of getting online communication with the young filmmakers in all parts of the Scandinavian countries offers ease, both because it is practical and is an appropriation of a meeting platform that is familiar to our participants.

\section{Conclusions and perspectives}

Herein, we have highlighted methodological implications in our research design and presented a brief overview of learning contexts for young filmmakers in Scandinavia. In particular we have showed and discussed how we conducted online interviews by using MSN. The overall goal for this study (2008-09) is to gain insight into how and where young Scandinavian filmmakers make learning paths and perhaps develop their interest in becoming professional filmmakers. We hope to contribute generally to the film and media pedagogic tradition in the Scandinavian countries and that our contributions will be pertinent for developing the academic discussion on the complex notions of learning and mediated learning. 


\section{References}

Banks, M. (2001) Visual Methods in Social Research. London: Sage.

Buckingham, D. (2003) Media education - literacy, learning and contemporary culture. London: Polity press.

Buckingham, D. (2007) Media education goes digital: an introduction. In: Learning, Media and Technology. 32 (2), June 2007: 111-119. London: Taylor and Francis.

Buckingham, D. \& Sefton-Green, J. (1994) Cultural studies goes to school - Reading and Teaching Popular Media. London: Taylor \& Francis.

Buckingham, D., Grahame, J. \& Sefton-Green, J. (1995) Making Media - Practical Production in Media Education. London: The English and Media Centre.

Burn, A. \& Durran, J. (2006) Digital anatomies: Analysis as Production in Media Education. In Buckingham, D. \& R. Willett (Eds.): Digital generations - Children, Young People, and New Media. London: Lawrence Erlbaum Assoc.

Burn, A. \& Durran, J. (2007) Media literacy in Schools - practice, production and progression. London: Paul Chapman Publishing.

Burn, A. \& Parker, D. (2003) Analysing media texts. London: New York: Continuum.

Burn, A. \& Reid, M. (2001) The Kineikonic Mode. http://www.open.ac.uk/eci/burn/featext.html

Colley, H., Hodkinson, P., Malcolm, J. (2004) Non-formal learning: mapping the conceptual terrain. Available in the informal education archives: http://www.infed.org/archives/e-texts/colley_informal_learning.htm

Drotner, K. (1999) Unge, medier og modernitet - pejlinger i et forandreligt landskab. Valby: Borgen/Medier.

Drotner, K. (2001) Medier for fremtiden. Copenhagen: Høst \& Søn.

Drotner, K. (2003a) At skabe sig - selv: Ungdom, astetik, predagogik. Second ed. Copenhagen: Gyldendal.

Drotner, K. (2003b) Disney i Danmark: At vokse op med en mediegigant. Copenhagen: Høst \& Søn.

Drotner, K. \& S. Livingstone (Eds.). (2008) International handbook on Children, Media and Culture. London: Sage Publications.

Erstad, O., deLange T., Gilje, Ø. (2007a) "Re-defining media learning - multiliteracies and digital production in Norwegian media education". In: Learning, Media and Technology. 32 (2), June 2007: 183-198.

Erstad, O., deLange, T., Gilje, Ø. (2007b) Morgendagens medieprodusenter. Rapport. Universitetet i Oslo.

Erstad, O. \& Gilje, Ø. (2008) Regaining Impact - Media Education and Media Literacy in a Norwegian Context. In Nordicom review 29 (2): 219-230.

Frølunde, L., Gilje, Ø., Lindstrand, F., Öhman-Gullberg, L. (2007) "Multimodal perspectives on moving image production by young people- Four Nordic studies of transformative processes in the work with film", abstract in conference proceedings and paper presented at NordMedia 2007 (17-19 August): University of Helsinki

Frølunde, L. (2009). Animated symbols: A study of how young people design animated films and transform meanings, $\mathrm{PhD}$ thesis, the Danish School of Education, Aarhus University, Copenhagen.

Gilje, Ø., Frølunde, L., Lindstrand, F. \& Öhman-Gullberg, L. (forthcoming 2009) "Mapping filmmaking; portraits of young filmmakers in Scandinavia using various contexts for learning filmmaking", In: Arnolds-Granlund, B.; O. Erstad, L. Högberg, S. Kotilainen, P. Lundgren \& B. Tufte (Eds) Media Literacy and Education: Nordic Perspectives. Helsingfors: Nordicom \& the Finnish Society on Media Education.

Halpern, R. (2008) The Means to Grow Up: Reinventing Apprenticeship as a Developmental Support in Adolescence. London: Taylor \& Francis

Hine, C. (2000) Virtual Ethnography. London: Sage Publications

Hodge, R. \& Kress, G. (1988) Social Semiotics. Cambridge: Polity Press.

Hull, G. (2003) At last: Youth culture and digital media: New literacies for new times. In Research in the Teaching of English, 38(2): 229-233.

Hull, G. \& Kenney, N.L. (2008) Hopeful children, Hybrid Spaces: Learning with Media after School. In Drotner, K., H.S. Jensen and K.C. Schrøder (Eds.) Informal Learning and Digital Media. Newcastle: Cambridge Scholar Publishing. 
Hull, G.A., \& Nelson, M.E. (2005) Locating the semiotic power of multimodality. Written Communication, 22(2), pp. 224-261.

Kearney, M.C. (2006) Girls make media. New York: London: Routledge.

Kress, G. (2003) Literacy in the New Media Age. London: Routledge.

Kress, G.; Jewitt, C.; Ogborn, J.; Tsatsarelis, C. (2001) Multimodal Teaching and Learning. The Rhetorics of the Science Classroom. London: Continuum.

Kress, G. \& van Leeuwen, T. (2001) Multimodal Discourse. The modes and media of contemporary communication. London: Arnold.

Kvale, S. (1996) Interview: An introduction to qualitative research interviewing. London: Sage.

Lindstrand, F. (2006) Att göra skillnad. Representation, identitet och lärande i ungdomars arbete och berättande med film. (Making difference. Representation, identity and learning in teenagers' work and communication with film). Stockholm: HLS Förlag.

Lindstrand, F. (2008) “Interview with Gunther Kress”. In Designs for Learning, 1 (2), pp. 60-71.

Livingstone, S. (2002) Young people and new media. London: Sage.

Loveless, A.M. (2007) Report 4 update: Creativity, technology and learning - a review of recent literature. Bristol: NESTA Futurelab.

Lüders, M. (2007) Being in mediated spaces. PhD thesis, University of Oslo. Summary available on: http://home. no.net/marika75/log/

Markham, A.N. (1998) Life Online: Researching Real Experiences in Virtual Space. Walnut Creek, California: AltaMira Press.

Sefton-Green, J. \& Buckingham, D. (1998) Digital Visions: Children's 'Creative' Uses of Multimedia Technologies. In Sefton-Green, J. (Eds.),: Digital Diversions - Youth culture in the Age of Multimedia. London: Routledge.

Pink, S. (2001) Doing Visual Ethnography. London: Sage Publications

Pink, S. (2006) The future of visual ethnography - engaging the senses. New York: Routledge.

Potter, J. (2006) "Technology and education: Debates, contexts and computers". In Sharp, J., S. Ward and L. Hankin (Eds.) Education Studies: an Issues-Based Approach, Learning Matters, Exeter

Reid, M. \& Burn, A. (2002) Evaluation Report of the Becta Digital Video Pilot Project. BECTA/BFI Available on: http://www.becta.org.uk/page_documents/research/dvreport_241002.pdf

Scollon R. and Scollon, S.W. (2004) Nexus Analysis: Discourse and the Emerging Internet. London: Routledge

Sefton-Green, J. (2004) Literature Review in Informal Learning with Technology Outside School. NESTA Futurelab series. Report 7.

Sefton-Green, J. (2008) Informal learning: a solution in search of a problem? In Drotner, K., H.S. Jensen and K.C. Schrøder (Eds) Informal Learning and Digital Media. Newcastle: Cambridge Scholar Publishing. Turkle, S. (1995)

Life on screen - Identity in the age of Internet. New York: Simon and Schuster Paperbacks.

Turkle, S. (1995) Life on the screen: identity in the age of the Internet. New York: Simon \& Schuster.

van Leeuwen, T. (2005) Introducing Social Semiotics. London: Routledge.

Wenger, E. (1998) Communities of Practice: Learning, Meaning, and Identity. Cambridge: Cambridge University Press

Öhman-Gullberg, L. (2008) Laddade bilder - Representation och meningsskapande i unga tjejers filmberättande. Doktorsavhandling i didaktik vid Stockholms universitet. Stockholm .

\section{Notes}

1. MSN is a free program for chatting, also called Windows Messenger.

2. Medietilsynet - rådet for anvendt medieforskning (www.ram.no). 
3. Herein, we use the term moving image production interchangeably with other terms: filmmaking production, moviemaking, digital media production, and multimodal design processes, albeit there are theoretical distinctions.

4. The survey data, (an online questionnaire), was gathered April- June 2008 using the online application QuestBack.

5. Two of the informants sent us a film that they had made together. So we have 29 informants, but 28 films in total.

6. The online MSN-interviews were saved as .rtf-files and coded using TAMS Analyzer, an open source software facilitating qualitative data analyses. Further information on analysis, publications and a report are available on: www.multimodalfilmmaking.tk 